РУДАКОВА Екатерина Константиновна - кандидат политических наук, старший научный сотрудник Нижегородского государственного лингвистического университета им. Н.А. Добролюбова (603155, Россия, г. Нижний Новгород, ул. Минина, 31a; kafedra_mo_nglu@mail.ru)

УСТИНКИН Сергей Васильевич - доктор исторических наук, профессор; директор Приволжского филиала ФНИСЦ РАН (603000, Россия, г. Нижний Новгород, Холодный пер., 4); начальник международной междисциплинарной научно-исследовательской лаборатории изучения мировых и региональных социально-политических процессов, научный руководитель Высшей школы международных отношений и мировой политики Нижегородского государственного лингвистического университета им. Н.А. Добролюбова (603950, Россия, г. Нижний Новгород, ул. Минина, 31a; sv.ustinkin@gmail.com)

\title{
МЕЖДУНАРОДНЫЙ ОПЫТ НОРМАТИВНО- ПРАВОВОГО РЕГУЛИРОВАНИЯ ПРАВА ВРАЧА НА СВОБОДУ СОВЕСТИ
}

\begin{abstract}
Аннотация. В статье представлен обзор международной практики нормативно-правового регулирования права врачей на отказ по соображениям совести. Данная тема находится на стыке правозащитной проблематики и медицинской этики. Особую актуальность дискуссия о правах врачей и медицинских работников приобретает в контексте внедрения новых медицинских технологий, многие из которых вызывают серьезную международную полемику о допустимости их использования в лечебной практике и моральное сопротивление у врачей, по соображениям совести отказывающихся от их применения. Исследование опирается на международное и национальное законодательство США, Польши, Германии, Италии, Швеции, России в области медицинской этики, данные социологических опросов медицинских работников и студентов-медиков и представляет аналитический обзор публикаций ведущих изданий в области биоэтики и медицинской этики.
\end{abstract}

Ключевые слова: биоэтика, медицинская этика, права человека, свобода совести, свобода вероисповедания, репродукция, демографическая безопасность

B международной практике отказ врача по соображениям совести (conscientious objection in medicine) относится к праву поставщиков медицинских услуг отказаться от определенных видов медицинского вмешательства, против которых они возражают по религиозным или моральным причинам. Самыми чувствительными для обсуждения являются отказы от процедур аборта и эвтаназии, напрямую затрагивающих право пациента на жизнь, в т.ч. в пренатальный период [Keogh et al. 2019; Savulescu 2006]. Со времен Гиппократа этический кодекс не позволял врачу соучаствовать в убийстве человека или плода в утробе матери: «Я не дам никому просимого у меня смертельного средства и не покажу пути для подобного замысла; точно так же я не вручу никакой женщине абортивного пессария»; «в какой бы дом я ни вошел, я войду туда для пользы больного, будучи далек от всего намеренного, неправедного и пагубного» [Гиппократ 1936: 43-46].

Право врача на отказ по соображениям совести не регулируется международным законодательством [Keogh et al. 2019]. Отсутствуют единые международно признанные нормы, за исключением права на свободу совести и вероисповедания ${ }^{1}$, а также некоторых рекомендаций в отношении отдельных видов медицинского вмешательства. Право на отказ от аборта закреплено в п. 8 Декларации $B M A$ : «Врачи имеют право на отказ от проведения аборта по сооб-

\footnotetext{
1 Всеобщая декларация прав человека от 10 декабря 1948 г. Доступ: https://www.un.org/ru/ documents/decl_conv/declarations/declhr.shtml (проверено 21.05.2021).
} 
ражениям совести, поэтому они могут отказаться от него, обеспечив непрерывность медицинской помощи квалифицированным коллегой» ${ }^{1}$. Ограничения содержатся в Резолюции ПАСЕ № 1763, в документе декларируется, что «ни одно лицо, больница или учреждение не может быть принуждено, привлечено к ответственности или подвергнуто дискриминации каким бы то ни было образом в связи с отказом в проведении, размещении, оказании помощи или в связи с абортом, искусственным выкидышем, эвтаназией или любым действием, которое может привести к смерти человеческого плода или эмбриона по любой причине» 2 .

Одним из препятствий легализации права врача на отказ по соображениям совести является установленное законом обязательство недопустимости отказа в экстренной медицинской помощи. Противники легализации врачебного отказа по соображениям совести приводят следующие аргументы: 1) отказ по соображениям совести не имеет веских научных оснований, кроме религиозно мотивированных ценностно-мировоззренческих соображений [Fiala, Arthur 2017]; 2) позиция, при которой права врача ставятся выше прав пациента, недопустима в современной медицине [Keogh et al. 2019]; 3) легализация отказа по соображениям совести создает благоприятные условия для развития различных дискриминаций [Wilson 2014]. Основными аргументами защитников легализации врачебного отказа по соображениям совести являются: 1) право человека на свободу совести и вероисповедания; 2) отсутствие правовой и этической оценки в отношении целого ряда медицинских технологий, вызывающих моральное сопротивление врачей; 3) несоответствие некоторых медицинских технологий нормам международного права [Рудакова, Шумакова 2020]. По мнению правозащитников, аргументы обеих сторон не являются взаимоисключающими, могут сосуществовать в единой правовой системе [Ben-Moshe 2019]. Многие сторонники легализации права на отказ по соображениям совести признают недопустимость отказа пациенту в экстренной медицинской помощи.

В США дискуссия на тему врачебного отказа по соображениям совести является традиционным камнем преткновения в медицинских кругах [Eberl 2019]. Эта проблема стала особенно острой в годы правления президента Трампа после его решения о создании отдела совести и религиозной свободы в рамках Департамента социальной службы [Eberl 2019], что должно было способствовать расширению уже закрепленного права медицинских работников на отказ по соображениям совести. Против данного решения был подан иск со стороны 19 штатов, округа Колумбии и различных организаций здравоохранения, в т.ч. и со стороны Американского колледжа акушеров и гинекологов (The American College of Obstetricians and Gynecologists), Американской ассоциации планирования семьи (Planned Parenthood). Суд США отклонил решение президента, судья Пол Энгельмайер назвал правило, которое расширило бы возможности медицинских работников отказываться от проведения медицинских процедур по убеждениям совести, «произвольным и капризным» 3 .

1 WMA Statement on Medically-Indicated Termination of Pregnancy. Adopted by the $24^{\text {th }}$ World Medical Assembly, August 1970 (2018). URL: https://www.wma.net/policies-post/wmadeclaration-on-therapeutic-abortion/ (accessed 21.05.2021).

2 Parliamentary Assembly Resolution 1763. The Right to Conscientious Objection in Lawful Medical Care. 2010. URL: http://www.assembly.coe.int/nw/xml/News/FeaturesManager-ViewEn.asp?ID=950 (accessed 21.05.2021).

3 Henry T. 2019. Why the HHS Conscience-rights Rule Was Blocked in Court. 2019, December 11. URL: https://www.ama-assn.org/health-care-advocacy/judicial-advocacy/whyhhs-conscience-rights-rule-was-blocked-court (accessed 21.05.2021). 
Основные аргументы противников легализации, обозначенные в иске, сводились к тому, что защита совести врачей должна быть сбалансирована обязательствами медицинской профессии; правило о свободе совести врача противоречит законам об абортах, вазэктомии, вакцинах и эвтаназии; правило резко расширит число отказов по религиозным и моральным основаниям, поставит под угрозу жизнь и безопасность людей, приведет к дискриминации социальных меньшинств 1 .

За поддержку права врача на отказ по соображениям совести выступает Американская медицинская ассоциация (АМА) - старейшее сообщество врачей и студентов-медиков США. Члены Ассоциации неоднократно подчеркивали, что свобода врачей действовать по совести не безгранична, если речь идет о необходимости экстренного спасения жизни и в условиях отсутствия альтернативы получения врачебной помощи. При этом сохранение возможности для врачей действовать в соответствии с убеждениями совести имеет большое значение для медицинской профессии ${ }^{2}$. Члены АМА неоднократно высказывали точку зрения в отношении права врача на отказ от эвтаназии, подчеркивая, что самоубийство с помощью врача в корне несовместимо с ролью врача как целителя ${ }^{3}$. АМА настаивает, что необходим поиск сбалансированного подхода, который позволит врачам выполнять свои фундаментальные обязанности 4 .

В Польше право врача на отказ по соображениям совести закреплено в ст. 39 закона «О профессии врача и врача-стоматолога»: «Врач может воздержаться от выполнения медицинских процедур, несовместимых с его совестью», при этом в ст. 30 отмечается обязанность оказания экстренной медицинской помощи: «Врач обязан оказывать помощь в любом случае, когда промедление в ее оказании может привести к опасности потери жизни, тяжелой травме или тяжелому расстройству здоровья» ${ }^{5}$. Госсекретарь министерства здравоохранения Польши, депутат Европарламента Болеслав Пьеха говорит о том, что «врачи в Польше имеют право отказаться от прерывания беременности, в Кодексе медицинской этики это называется “оговоркой совести” и допускается польским законодательством». Он подчеркивает, что ситуация с возможностью реализовать данное право не улучшается: «В прежние времена врачи тоже могли отказаться по причинам совести, однако сегодня такие врачи становятся объектом остракизма в СМИ, и мне это не нравится» 6 .

В Германии врач не может быть принужден к выполнению процедур, противоречащих убеждениям совести. Врач-гинеколог Джаннинг Вагнер отмечает: «Прерывание беременности не является принуждением в Германии. Даже

1 Weiser B., Sanger-Katz M. 2019. Judge Voids Trump-Backed 'Conscience Rule' for Health Workers. - The New York Times. 2019, 06 November. URL: https://www.nytimes.com/2019/11/06/ upshot/trump-conscience-rule-overturned.html (accessed 21.05.2021).

2 AMA. HHS should withdraw proposal on health care conscience rights. 2018. URL: https://www.ama-assn.org/delivering-care/ethics/hhs-should-withdraw-proposal-health-careconscience-rights (accessed 21.05.2021).

3 Physician-Assisted Suicide. American Medical Association. 2019, December 11. URL: https:// www.ama-assn.org/delivering-care/ethics/physician-assisted-suicide (accessed 21.05.2021).

4 AMA. HHS should withdraw proposal on health care conscience rights. 2018. URL: https://www.ama-assn.org/delivering-care/ethics/hhs-should-withdraw-proposal-health-careconscience-rights (accessed 21.05.2021).

5 Ustawa o zawodach lekarza i lekarza dentysty z dnia 5 grudnia 1996 r. System Informacji Prawnej. 2020. URL: https://www.lexlege.pl/ustawa-o-zawodach-lekarza-i-lekarza-dentysty/art39/ (accessed 21.05.2021).

6 Rozmowa z Bolesławem Piechą. Byłem jak doktor Jekyll i mister Hyde. 2007, July. URL: https://www.gosc.pl/doc/761948. Bylem-jak-doktor-Jekyll-i-m (accessed 21.05.2021). 
главный врач не может определить, кто проводит операцию, для этого нет и договорных обязательств. Есть коллеги, которые этого не делают, есть конфессиональные клиники, в которых аборты не производятся, но есть множество частных клиник и врачей, которые специализируются только на абортах» ${ }^{1}$. Закон об усовершенствовании информации о прерывании беременности обязует регистрироваться и предоставлять информацию все клиники Германии, делающие аборты, а система консультационных центров исключает возможность направления женщины к врачу, который по соображениям совести не делает аборты ${ }^{2}$. Немецкие врачи отмечают рост числа абортов в Германии, при этом наблюдается снижение готовности самих врачей делать аборты. По мнению доктора Габриэля Хальдера, все меньше врачей готовы проводить аборты; из 18,5 тыс. практикующих врачей-гинекологов аборты в Германии проводят 1,2 тыс. ${ }^{3}$ Программа крупнейшего медицинского учебного заведения Шарите не содержит обязательных курсов по прерыванию беременности и эвтаназии. В связи с этим министр социальных дел и сторонник абортов Манне Луч выступил с инициативой ввести зависимость найма врачей в государственные клиники от готовности делать аборты. Эту позицию критикуют врачи, говоря, что нельзя обязывать человека делать то, что не представляется этически возможным ${ }^{4}$.

В Италии министерство здравоохранения борется за сохранение права врача на отказ от абортов, врачи Италии могут заявить отказ от аборта в письменной форме без объяснения причин. По данным 2015 г., в Италии правом на отказ пользуются в среднем до 70\% гинекологов [Minerva 2015]. В вопросе легализации права врача на отказ Италия придерживается принципа «отсутствие корреляции» (no correlation argument) [Bo, Zotti, Charrier 2017]. Впервые данный принцип был озвучен в решении комитета по биоэтике Италии в ответ на обвинения Европейского комитета по социальным правам в нарушении Италией Европейской конвенции о социальных правах: «Право итальянских врачей на отказ по соображениям совести от аборта делает безопасный, легальный и доступный выход недоступным для большинства итальянских женщин». Комитет по биоэтике Италии $(C N B)$ в ответ на данное обвинение принял заключение об «отсутствии взаимосвязи»: «Право врача на отказ по соображениям совести от аборта не ущемляет право женщин на аборт, эти две правовые нормы не взаимосвязаны». Правительство Италии признает, что теоретически доля врачей-отказников может увеличиться, при этом сократится число специалистов, готовых делать аборты, и государство не сможет гарантировать право женщинам на аборт. По некоторым данным, в регионах Абруцци и Лациуме - 80,7\% отказов врачей от абортов, в Молизе -93,3\% [Bo, Zotti, Charrier 2017]. Таким образом, в Италии принципы репродуктивной автономии и право женщин на аборт имеют относительную ценность по сравнению с убеждениями совести врача, а право врача на отказ по

\footnotetext{
1 Der Tagesspiegel. Arzt: „Ich will Frauen in jeder Situation helfen“. 2008. URL: https:// www.tagesspiegel.de/gesellschaft/panorama/abtreibung-arzt-ich-will-frauen-in-jeder-situationhelfen/1387530.html (accessed 21.05.2021).

2 German Medical Association. Liste von Ärzten, Krankenhäusern und medizinischen Einrichtungen nach $\S 13$ Abs. 3 Schwangerschaftskonfliktgesetz (2019). URL: https://www. bundesaerztekammer.de/aerzte/versorgung/schwangerschaftsabbruch (accessed 21.05.2021).

3 ,Für die Wahlfreiheit von Frauen' (n.d.). URL: https://taz.de/Schwangerschaftsabbrueche/!5640807 (accessed 21.05.2021).

4 ,Geisteskranke Volkstodphantasien: Grüne wollen Ärzte zu Abtreibungen zwingen‘. 2020. URL: https://www.anonymousnews.ru/2020/08/14/gruene-aerzte-abtreibungen-zwingen (accessed 21.05.2021).
} 
соображениям совести не ставится в зависимость от прав пациента на получение медицинской помощи.

В Скандинавских странах, таких как Швеция, отказ по соображениям совести не является законодательно закрепленным правом [Munthe 2016]. Шведский медицинский работник, отказывающийся выполнять законную процедуру на основании моральных убеждений или религиозных мировоззрений, может получить выговор или даже лишиться работы. Нелегитимность отказа по соображениям совести затрагивает не только медицинскую сферу, но также и другие профессии, связанные с оказанием услуг населению. Одной из причин такого решения являются экономические соображения: оказание услуг в полном объеме в наикратчайшие возможные сроки является основополагающим тезисом эффективной работы в Швеции [Munthe 2016]. Некоторые работодатели готовы в индивидуальном порядке рассматривать отказы по соображениям совести, но это является добровольным решением.

В России право врача на отказ закреплено в ст. 70 Ф3 «Об основах охраны здоровья граждан в Российской Федерации», врач в России имеет право на отказ от процедуры проведения искусственного прерывания беременности, «если речь не идет об угрозе жизни пациента и здоровья окружающих, а также в том случае, если есть другие врачи, которые могут выполнить процедуру» ${ }^{1}$. В качестве причин этического характера отказа могут быть обозначены «недостижимость терапевтического сотрудничества с пациентом» и «отсутствие психологического контакта» 2 . На практике доминирует принцип «недопустимости отказа в экстренной медицинской помощи» (ст. 11 Ф3): «Медицинская помощь в экстренной форме оказывается медицинской организацией и медицинским работником гражданину безотлагательно и бесплатно. Отказ в ее оказании не допускается». В ст. 124 Уголовного кодекса РФ подобный отказ квалифицируется как уголовное деяние ${ }^{3}$. В России запрещена эвтаназия (ст. 45, 71 Ф3): «Медицинским работникам запрещается осуществление эвтаназии, то есть ускорение по просьбе пациента его смерти какими-либо действиями (бездействием) или средствами, в том числе прекращение искусственных мероприятий по поддержанию жизни пациента» 4 .

Самой чувствительной является проблема психологических последствий для врача от выполнения медицинских процедур против убеждений совести. Немногие организации, такие как Hilfe zum Liben и Pro Familia, предоставляют эмпирические данные на эту тему. Так, до сих пор постабортный синдром описывался в учебниках только применительно к женщинам, но никогда применительно к тем, кто его выполняет. Есть научные данные, подтверждающие, что принуждение врача действовать против убеждений совести негуманно [Wicclair 2017], об этом свидетельствуют материалы из включенных интервью с врачами, которые выполняли аборты против убеждений совести: «я чувствовал тотальный дискомфорт», «начались проблемы с алкоголем», «я понимала, что больше не могу этого делать, но долг врача обязывал», «глядя на своих детей,

1 Федеральный закон «Об основах охраны здоровья граждан в Российской Федерации» от 21.11.2011 N 323-Ф3 (ред. от 31.07.2020) (с изм. и доп., вступ. в силу с 01.09.2020). Доступ: http://www.consultant.ru/document/cons_doc_LAW_121895 (проверено 21.05.2021).

2 Кодекс этики российского врача. Утвержден 4-й Ассоциацией врачей России. М., 1994. Доступ: https://onf.ru/2013/05/30/kodeks-e-tiki-rossijskogo-vracha (проверено 21.05.2021).

3 Уголовный кодекс РФ от 13.06.1996 N 63-Ф3 (ред. 31.07.2020). Ст. 124. Доступ: http:// www.consultant.ru/document/cons_doc_LAW_10699/(проверено 21.05.2021).

4 Федеральный закон «Об основах охраны здоровья граждан в Российской Федерации» от 21.11.2011 N 323-Ф3 (ред. от 31.07.2020) (с изм. и доп., вступ. в силу с 01.09.2020). Доступ: http://www.consultant.ru/document/cons_doc_LAW_121895 (проверено 21.05.2021). 
я думала, что не заслуживаю этого счастья», «я помню каждую несостоявшуюся маму», «данная процедура оставила глубокий след в душе», «мое сердце до сих пор болит и обливается кровью», «я не могу вытеснить факт убийства в подсознание» 1 .

Могут ли убеждения совести стать в будущем препятствием для освоения профессии врача, привести к дискриминации при приеме на работу, со стороны коллег и руководства? Около 45,2\% студентов-медиков Великобритании (из 1437 отпрошенных респондентов) считают, что врачи должны иметь право возражать против любой процедуры, в отношении которой у них есть моральные, культурные и религиозные разногласия. Для студентов самых разных конфессий возможность отказа по соображениям совести является важной составляющей будущей профессии, при этом 40\% отметили, что существуют пределы отказа, связанные с экстренной медицинской помощью [Strickland 2012]. Финские врачи-гинекологи, несмотря на отсутствие в Финляндии права на отказ, в 34,2\% случаев поддержали бы его введение, $62,4 \%$ врачей готовы работать с теми коллегами, которые имеют убеждения совести и используют право на отказ [Nieminen et al. 2015]. Студенты религиозных заведений Чили в 52\% поддерживают законодательное право на отказ, в светских учреждениях эта цифра гораздо меньше - 20\%, только $18 \%$ воспользовались бы им лично. Такие показатели связаны с тем, что Чили в 2017 г. впервые отменила запрет на аборты и общественное мнение сегодня находится на стороне сторонников права женщин на аборт [Biggs et al. 2020]. В Испании более 50\% из 432 студентов университета Ла-Коруньи заявили, что верят в право добросовестно возражать против любой процедуры [López et al. 2016].

По мнению многих ученых, моральные и этические принципы работников медицинских профессии должны учитываться [Wicclair 2017], а основной конфликт современной медицины заключается в утрате ориентации на благополучие пациента и первичной ориентации на экономическую выгоду от проведения платных медицинских процедур [Wils, Baumann-Hölzle 2019]. И если вопрос о том, является ли врач способным на непредвзятое решение в вопросах этики жизни и смерти, остается открытым, с точки зрения общегражданских свобод каждый человек имеет право на свободу совести и вероисповедания, а морально-этические права, если они не противоречат основным законам государства, должны быть доступны людям любых профессий.

Как показал опыт других стран, законодательно регулировать вопросы совести в медицинских профессиях сложно, но достичь баланса прав врача и пациента возможно. Право на отказ по соображениям совести может быть закреплено законодательно, при этом приоритетным должен оставаться принцип недопустимости отказа в экстренной медицинской помощи. Необходимо также преодолеть вакуум в правовой и этической оценке в отношении целого ряда медицинских технологий, обеспечить доступ врачам и пациентам к достоверным научным знаниям о последствиях для здоровья в результате применения новых медицинских технологий. Следует выявить сценарии, при которых баланс сил может резко нарушаться, в этом случае важно определить степень вмешательства (или невмешательства) государства. Необходима слаженная работа органов, способных помочь урегулировать конфликт интересов врача

\footnotetext{
1 Rozmowa z Bolesławem Piechą. Byłem jak doktor Jekyll i mister Hyde. 2007, July. URL: https://www.gosc.pl/doc/761948.Bylem-jak-doktor-Jekyll-i-m; Адашевић С. Абортус је убиство. URL: https://www.sedmica.me/dr-stojan-adasevic-abortus-je-ubistvo-evo-zasto/ (accessed 21.05.2021).
} 
и пациента, должен существовать вариант процессуальной охраны против злоупотребления правом отказа по соображениям совести.

\section{Список литературы}

Гиппократ. 1936. Избранные книги (пер. проф. В.И. Руднева). М. Доступ: https://rusneb.ru/catalog/000199_000009_005274224_1000221917

Рудакова Е.К., Шумакова О.Н.2020. Правовые и этические проблемы использования вспомогательных репродуктивных технологий в зарубежном дискурсе в контексте демографической безопасности России. - Власть. Т. 28. № 2. C. 138-145.

Ben-Moshe N. 2019. The Truth behind Conscientious Objection in Medicine. Journal of Medical Ethics. Vol. 45 (2019). P. 404-410.

Biggs A., Casas L., Ramm A., Finley Baba C., Correa S.P. 2020. Medical and Midwifery Students' Views on the Use of Conscientious Objection in Abortion Care, Following Legal Reform in Chile: a cross-sectional study. - BMC Medical Ethics. Vol. 21. P. 1-11.

Bo M., Zotti C.M., Charrier L. 2017. The No Correlation Argument: Can the Morality of Conscientious Objection Be Empirically Supported? The Italian case. BMC Medical Ethics. Vol. 18.No. 1.

Eberl J.T. 2019. Conscientious Objection in Health Care. - Theoretical Medicine and Bioethics. Vol. 40 (2019). P. 483-486.

Fiala C., Arthur J.H. 2017. There Is No Defense for 'Conscientious Objection' in Reproductive Health Care. - European Journal of Obstetrics \& Gynecology and Reproductive Biology. Vol. 216. P. 254-258.

Keogh L.A. et al. 2019. Conscientious Objection to Abortion, the Law and Its Implementation in Victoria, Australia: Perspectives of Abortion Service Providers. BMC Med Ethics. Vol. 20. Is. 11.

López D.L. et al. 2016. Conscientious Objection in Spanish Podiatrists Students: a Questionnaire Survey. - Acta Bioethica. Vol. 22. Is. 2. P. 341-345.

Minerva F. 2015. Conscientious Objection in Italy. - Journal of Medical Ethics. Vol. 41. P. 170-173.

Munthe C. 2016. Conscientious Refusal in Healthcare: the Swedish Solution. Journal of Medical Ethics. Vol. 43. No. 4. P. 257-259.

Nieminen P., Lappalainen S., Ristimäki P., Myllykangas M., Mustonen M. 2015. Opinions on Conscientious Objection to Induced Abortion among Finnish Medical and Nursing Students and Professionals. - BMC Medical Ethics. Vol. 16. Article number: 17.

Savulescu Ju. 2006. Conscientious Objection in Medicine. - BMJ. 02 February. URL: https://www.bmj.com/content/332/7536/294.full

Strickland S. Lm. 2012. Conscientious Objection in Medical Students: a Questionnaire Survey. - Journal of Medical Ethics. Vol. 38. Is. 1. P. 22-25.

Wicclair M. 2017. Conscientious Objection in Healthcare and Moral Integrity. Cambridge Quarterly of Healthcare Ethics. Vol. 26. Is. 1. P. 7-17.

Wils J.P.; Baumann-Hölzle R. 2019. Die normative idee des gesundheitswesens. Ethik im Gesundheitswesen. Baden-Baden: NOMOS.

Wilson B. 2014. 'Conscience' or Discrimination? Healthcare Providers, Abortion and Moral Obligation. 2014, $8^{\text {th }}$ July. URL: https://www.wheelercentre.com/notes/ ce71251a56b3 (accessed 21.05.2021). 
RUDAKOVA Ekaterina Konstantinovna, Cand.Sci. (Pol.Sci.), Associate Professor, Senior Researcher at Dobroljubov State Linguistics University of Nizhny Novgorod (31a Minina St, Nizhny Novgorod, Russia, 603155); kafedra_mo_nglu@ mail.ru)

USTINKIN Sergey Vasilyevich, Dr.Sci. (Hist.), Professor; Director of the Volga Branch of the Federal Center of Theoretical and Applied Sociology, Russian Academy of Sciences (4 Holodny Lane, Nizhny Novgorod, Russia, 603000; Head of the International Cross-Disciplinary Laboratory for Studies of Global and Regional Sociopolitical Processes, Scientific Director of the Higher School of International Relations and World Politics, Dobroljubov State Linguistics University of Nizhny Novgorod (31a Minina St, Nizhny Novgorod, Russia, 603155); sv.ustinkin@gmail.com)

\title{
INTERNATIONAL EXPERIENCE OF LEGAL REGULATION OF THE RIGHT TO CONSCIENTIOUS OBJECTION IN MEDICINE
}

\begin{abstract}
This study provides an overview of international regulation of legal practices associated with conscientious objection in medicine. It explores the junctures of judgment in procedures for legal and ethical decisions in clinical medicine. The article presents an exploratory account of how health professionals adapt to new ethical practices and how these practices may become a challenge, raising ethical concerns and resistance from those involved, leading to broader debate about ethical principles in medicine. The concept of decision-making concerning conscientious objection in medicine was analyzed within the context of international and national laws in such countries as the USA, Poland, Germany, Italy, Sweden and Russia. In addition, the researchers provide an analytical review of secondary data from large surveys and studies in the field of bioethics and medical ethics.

Keywords: bioethics, medical ethics, human rights, freedom of conscience, freedom of religion, reproduction, demographic security
\end{abstract}

